\title{
NOTE ON THE UNILATERAL SURFACE OF MOEBIUS*
}

\author{
BY
}

\section{HEINRICH MASCHKE}

In order to construct an algebraic surface containing as a part the unilateral paper-strip of Moebius, $\dagger$ let a straight line $L$ move in space along a circle $C$, perpendicular to the tangents of $C$ and in such a way that, when the point of intersection $Q$ of $L$ with $C$ has described the full circle, the initial position of $L$ makes with its final position an angle of $180^{\circ}$. The condition that $L$ meets $C$ at right angles is equivalent to the condition that $L$ meets a straight line $A$ passing through the center $M$ of the circle and perpendicular to its plane; let $P$ be the movable point of intersection of $L$ and $A$. If now we add the further condition that the range $P$ on $A$ be projective to the range $Q$ on $C$ (e. $g$., by taking the angle $Q P M$ always half the angle of the arc described by $Q$ on $C$ ) then $L$ describes, according to a general theorem, $\ddagger$ a ruled surface of the third order.

Conversely: take any ruled surface $R$ of the third order, particular cases excepted, pass a plane section through one of the generators $L$ which will meet $R$ besides $L$ in a conic section $K$, and describe a curve $T$ on $R$ the points of which have along the generators a sufficiently small constant distance from $K$; then $T$ will cut out of $R$ a unilateral Moebius surface.

University of Chicago, November 15, 1899.

* Presented to the Society (Chicago) December 29, 1899. Received for publication November $15,1899$.

† MоквIUs: Ueber die Bestimmung des Inhalts eines Polyeders, $₹ 11$. (G esa m melte Werke e, vol. II, p. 484-485.)

$\ddagger$ REYE : Geometrie der Lage, ed. 3, vol. I, p. 209, no. 101. 